\title{
Resveratrol protects neuronal cells from isoflurane-induced inflammation and oxidative stress-associated death by attenuating apoptosis via Akt/p38 MAPK signaling
}

\author{
WEILAN HU ${ }^{1}$, EI YANG ${ }^{1}$, JIANXIN YE ${ }^{1}$, WEILI HAN ${ }^{1}$ and ZENG-LI DU ${ }^{2}$ \\ ${ }^{1}$ Department of Anesthesiology, Xinxiang Central Hospital of Henan Province, Xinxiang, Henan 453000; \\ ${ }^{2}$ Department of Anesthesiology, Coking Coal Central Hospital of Henan Province, Jiaozuo, Henan 454000, P.R. China
}

Received August 29, 2015; Accepted June 29, 2017

DOI: $10.3892 / \mathrm{etm} .2017 .5527$

\begin{abstract}
The aim of the present study was to determine whether resveratrol protects neuronal cells from inflammation and isoflurane-induced oxidative stress-associated death via attenuating apoptosis via Akt/p38 mitogen-activated protein kinase (MAPK) signaling. The PC12 rat pheochromocytoma cell line was treated with $2 \%$ isoflurane $+21 \% \mathrm{O}_{2}+5 \% \mathrm{CO}_{2}$ for $6 \mathrm{~h}$ and pre-treated with resveratrol $(0-1,000 \mu \mathrm{M})$ for 0 , 24 or $48 \mathrm{~h}$ prior to isoflurane treatment. An MTT assay, flow cytometry and ELISA of tumor necrosis factor- $\alpha$, interleukin-6, malondialdehyde and superoxide dismutase revealed that resveratrol reduced growth inhibition, restrained apoptosis and suppressed inflammation and oxidative stress induced by isoflurane in PC12 cells. Pretreatment with resveratrol effectively reduced caspase- 3 activity and inducible nitric oxide synthase protein expression in isoflurane-induced $\mathrm{PC} 12$ cells. In addition, western blot analysis demonstrated that resveratrol treatment significantly attenuated isoflurane-induced decreases in the activated phosphorylated (p)-Akt/Akt ratio and increases in the p-p38/p38 MAPK protein ratio in PC12 cells. These findings indicated that resveratrol was able to protect neuronal cells from isoflurane-induced inflammation and oxidative stress-associated death by attenuating apoptosis via Akt/p38 MAPK signaling.
\end{abstract}

\section{Introduction}

With high anesthetic efficacy, inhalation anesthetics, which allow for easy control of the depth of anesthesia, have been widely applied in a clinical setting for $>170$ years $(1,2)$. In the USA, the number of individuals receiving general anesthesia reaches 40 million each year.

Correspondence to: Mr. Zeng-Li Du, Department of Anesthesiology, Coking Coal Central Hospital of Henan Province, 169 Liberation Road, Jiaozuo, Henan 454000, P.R. China

E-mail: dun36363215427@126.com

Key words: resveratrol, isoflurane, neuronal cells, inflammation, oxidative stress
Isoflurane, the most widely used intravenous anesthetic in the clinic, takes effect rapidly and its action time is short with few untoward effects (3). It is therefore widely employed in surgical anesthesia and operations of diagnosis and treatment, such as minor surgery, gastrointestinal endoscopy and interventional therapy (4). Animal studies have demonstrated that isoflurane and inhalation anesthetics induce apoptosis of neurocytes in neonatal animals and further damage cognitive function (3). It was also clinically reported that isoflurane resulted in abnormal cognitive functions and behaviors (5). It was also reported to cause retrograde amnesia (5).

Isoflurane, which is safe and has good controllability, is one of the most widely used fluorinated inhalation anesthetics (6). The effect of isoflurane on the respiratory system is extensive and complex (6). It influences the pulmonary surfactant and inflammatory response of the lungs (7). The cytokine response is a key link of the early inflammatory response. With the accumulation of large amounts of inflammatory cytokines, lung injury during the peri-operative period is mainly an acute process (7). Expression of pro-inflammatory cytokines and imbalance of pro-inflammatory/anti-inflammatory cytokines has an essential role in lung injury during the peri-operative period (8).

The universal functions of resveratrol are based on its variability of site of action (9). Its sites of action include the cytomembrane, intra-cellular receptor, signaling molecules, enzymes, the oxidative system, the DNA repair system, transcription factors, cell proliferation, the cell cycle, differentiation and cell death $(10,11)$. Cellular signaling pathways convert stimuli to signals. This process involves a series of biochemical reactions. Resveratrol has functions of activating or inhibiting a series of signal transduction pathways (12). The present study investigated whether resveratrol protects anesthesia-induced neuronal cells from inflammation and oxidative stress-induced death, and explored the possible signaling pathways involved to elucidate the underlying mechanisms.

\section{Materials and methods}

Cell culture and model groups. The PC12 rat pheochromocytoma cell line was obtained from the Shanghai Cell Bank of the Chinese Academy of Sciences (Shanghai, China) and cultured in Dulbecco's modified Eagle's medium (DMEM; 
HyClone; GE Healthcare, Little Chalfont, UK) containing $10 \%$ fetal calf serum (Sigma-Aldrich; Merck KGaA, Darmstadt, Germany), $100 \mathrm{U} / \mathrm{ml}$ penicillin and $100 \mu \mathrm{g} / \mathrm{ml}$ streptomycin at $37^{\circ} \mathrm{C}$, in $5 \% \mathrm{CO}_{2}$ and $95 \%$ air. Isoflurane was delivered by an anesthesia machine (Datex-Ohmeda; GE Healthcare) to a sealed plastic box in a $37^{\circ} \mathrm{C}$ incubator containing 6- or 96-well plates, into which $\mathrm{PC} 12$ had been seeded at $1 \times 10^{6}$ and $5 \times 10^{3}$ cells/well, respectively. Following pretreatment with 10-1,000 $\mu \mathrm{M}$ resveratrol (Sigma-Aldrich; Merck KGaA) for 0, 24 and $48 \mathrm{~h}$ or DMEM as a control, PC12 cells were treated with $2 \%$ isoflurane $+21 \% \mathrm{O}_{2}+5 \% \mathrm{CO}_{2}$ for $6 \mathrm{~h}$, as described previously (13).

Determination of inhibition rate via MTT assay. Prior to isoflurane treatment, PC12 cells $\left(5 \times 10^{3}\right)$ were seeded into 96-well plates and $20 \mu \mathrm{l}$ MTT (5 mg/ml; Sigma-Aldrich; Merck $\mathrm{KGaA}$ ) was added into each well, followed by incubation for 4 h. Subsequently, $150 \mu$ l dimethyl sulfoxide (Sigma-Aldrich; Merck KGaA) was added into each well, followed by agitation for $20 \mathrm{~min}$. The optical density at $490 \mathrm{~nm}$ (OD490) was measured using an ELISA plate reader (Bio-Rad Laboratories, Inc., Hercules, CA, USA) and the inhibition rate was calculated as follows: [(OD490 control cells $\left.\left.-\mathrm{OD} 490_{\text {treated cells }}\right) / \mathrm{OD} 490_{\text {control cells }}\right]$ $\mathrm{x} 100 \%$.

Apoptosis assay. Prior to isoflurane treatment, PC12 cells $\left(1 \times 10^{6}\right)$ were seeded into 6-well plates to assess apoptosis. PC12 cells were incubated with Annexin V-fluorescein isothiocyanate and propidium iodide for $30 \mathrm{~min}$ in the dark. The apoptotic rate was analyzed using a flow cytometer (BD Biosciences, San Jose, CA, USA).

Determination of inflammation, oxidative stress and caspase-3 activity using ELISA. PC12 cells (1x10\%/well) were seeded into 6-well plates and subjected to isoflurane treatment. Interleukin (IL)-6, tumor necrosis factor (TNF)- $\alpha$, malondialdehyde (MDA) and superoxide dismutase (SOD) were assessed using IL-6 (EK-R30201) and TNF- $\alpha$ ELISA kits (EK-R31092; Shanghai Enzyme-linked Biotechnology Co., Shanghai, China) as well as MDA (A003-1) and SOD (A001-1-1) ELISA kits (Nanjing Jiancheng Bio-Engineering Institute Co., Ltd., Nanjing, China). Caspase-3 activity was determined using a Caspase-3 activity kit (C1116; Beyotime Institute of Biotechnology, Nanjing, China) according to the manufacturer's protocol. The ELISA plate reader was from Bio-Rad Laboratories, Inc.

Western blot analysis. PC12 cells (1x10\% into 6-well plates and subjected to isoflurane treatment. They were lysed in radioimmunoprecipitation lysis buffer (Beyotime Institute of Biotechnology) with protease and phosphatase inhibitor cocktail tablets (Roche, Mannheim, Germany). The lysate was centrifuged at $12,000 \mathrm{x} g$ for $25 \mathrm{~min}$ at $4^{\circ} \mathrm{C}$. The supernatant was collected to measure the protein concentration using a bicinchoninic acid protein assay kit (Beyotime Institute of Biotechnology). Protein samples $(50 \mu \mathrm{g}$ per lane) were resolved by $8-12 \%$ SDS-PAGE and transferred to a nitrocellulose membrane (EMD Millipore, Billerica, MA, USA) for $2 \mathrm{~h}$. Membranes were blocked using 5\% (w/v) skimmed milk in PBS containing 0.1\% Tween-20 (PBST) for

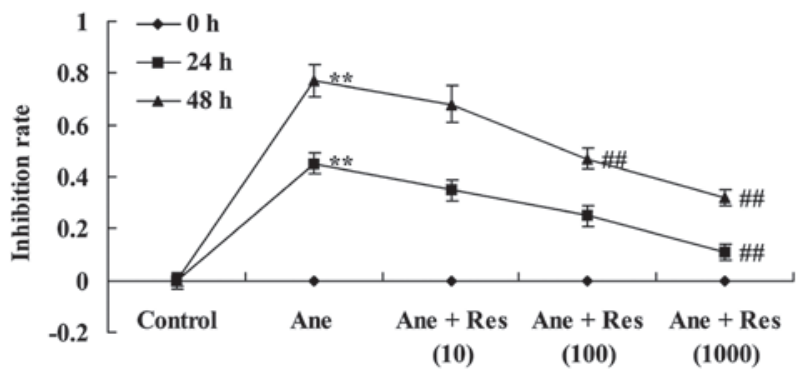

Figure 1. Resveratrol reduces isoflurane-induced growth inhibition of neuronal cells. Groups: Control, control group; Ane, anesthesia-induced model group; Ane + Res (10), $10 \mu \mathrm{M}$ resveratrol + anesthesia-induced model group; Ane + Res $(100), 100 \mu \mathrm{M}$ resveratrol + anesthesia-induced model group; Ane + Res $(1,000), 1,000 \mu \mathrm{M}$ resveratrol + anesthesia-induced model group. ${ }^{* *} \mathrm{P}<0.01$ compared with control group; ${ }^{\# \#} \mathrm{P}<0.01$ compared with Ane model group.

$1 \mathrm{~h}$ at room temperature and then incubated at $4^{\circ} \mathrm{C}$ overnight with anti-inducible nitric oxide synthase (iNOS; sc-649), phosphorylated (p)-Akt (sc-7985-R), Akt (sc-8312); p-p38 mitogen-activated protein kinase (MAPK; sc-17852-R) or $\beta$-actin (sc-7210) antibodies (all at 1:500 dilution; Santa Cruz Biotechnology, Inc., Dallas, TX, USA) in PBST with $5 \%$ skimmed milk for $1 \mathrm{~h}$ at $37^{\circ} \mathrm{C}$. Membranes were subsequently incubated with goat anti-rabbit horseradish peroxidase-conjugated secondary antibody (sc-2004; 1:2,000; Santa Cruz Biotechnology, Inc.) for $1 \mathrm{~h}$ at $37^{\circ} \mathrm{C}$, and observed using BeyoECL Plus (Beyotime Institute of Biotechnology) and quantified using Image Lab 3.0 software (Bio-Rad Laboratories, Inc.).

Statistical analysis. Values are expressed as the mean \pm standard deviation. One-way analysis of variance, followed by the Tukey multiple comparison test, was used to assess the statistical significance of differences between groups. SPSS version 17.0 (SPSS, Inc., Chicago, IL, USA) was used for data analysis and $\mathrm{P}<0.05$ was considered to indicate a statistically significant difference.

\section{Results}

Resveratrol reduces isoflurane-induced growth inhibition of neuronal cells. PC12 cells were treated with resveratrol for 24 or $48 \mathrm{~h}$ followed by isoflurane or control conditions for $6 \mathrm{~h}$. The effects of resveratrol on the isoflurane-induced inhibition of PC12 cells were determined using an MTT assay. A dose-dependent growth inhibition by isoflurane on PC12 cells was observed, which was reduced by treatment with resveratrol. Following pretreatment with $1,000 \mu \mathrm{M}$ resveratrol for 24 or $48 \mathrm{~h}$ as well as with $100 \mu \mathrm{M}$ resveratrol for $48 \mathrm{~h}$, the isoflurane-induced growth inhibition of PC12 cells was significantly reduced (Fig. 1).

Resveratrol protects neuronal cells from isoflurane-induced apoptosis. Prior to the anesthetic procedures, the effects of resveratrol on the apoptosis of isoflurane-induced PC12 cells were determined using flow cytometry. As presented in Fig. 2, isoflurane was observed to induce apoptosis of PC12 cells. Of note, pretreatment with resveratrol inhibited the 
A

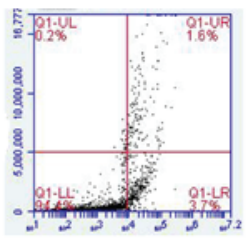

Control

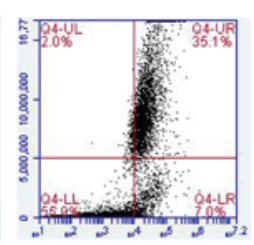

Ane

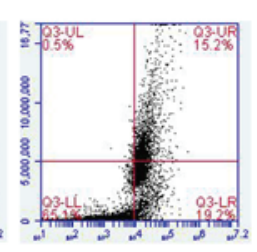

Ane + Res (10)

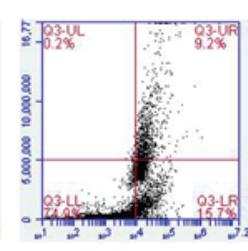

Ane + Res (100)

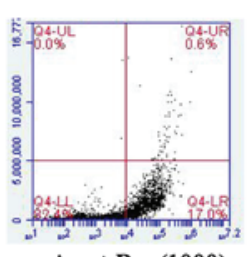

Ane + Res (1000)

B

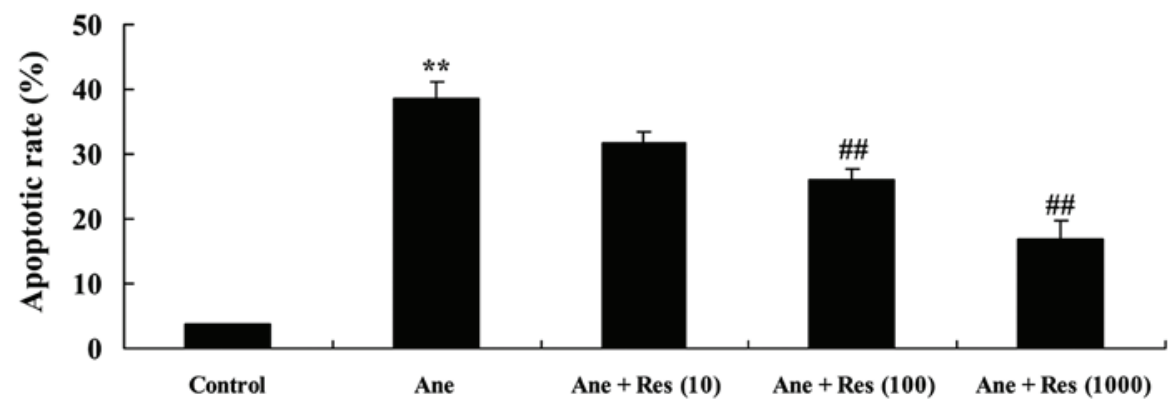

Figure 2. Resveratrol protects against isoflurane-induced apoptosis of neuronal cells. The apoptotic rate was determined by (A) flow cytometry and (B) quantified. Groups: Control, control group; Ane, anesthesia-induced model group; Ane + Res (10), $10 \mu \mathrm{M}$ resveratrol + anesthesia-induced model group; Ane + Res (100), $100 \mu \mathrm{M}$ resveratrol + anesthesia-induced model group; Ane + Res (1,000), 1,000 $\mu \mathrm{M}$ resveratrol + anesthesia-induced model group. ${ }^{* *} \mathrm{P}<0.01$ compared with control group; ${ }^{\# \#} \mathrm{P}<0.01$ compared with Ane model group.

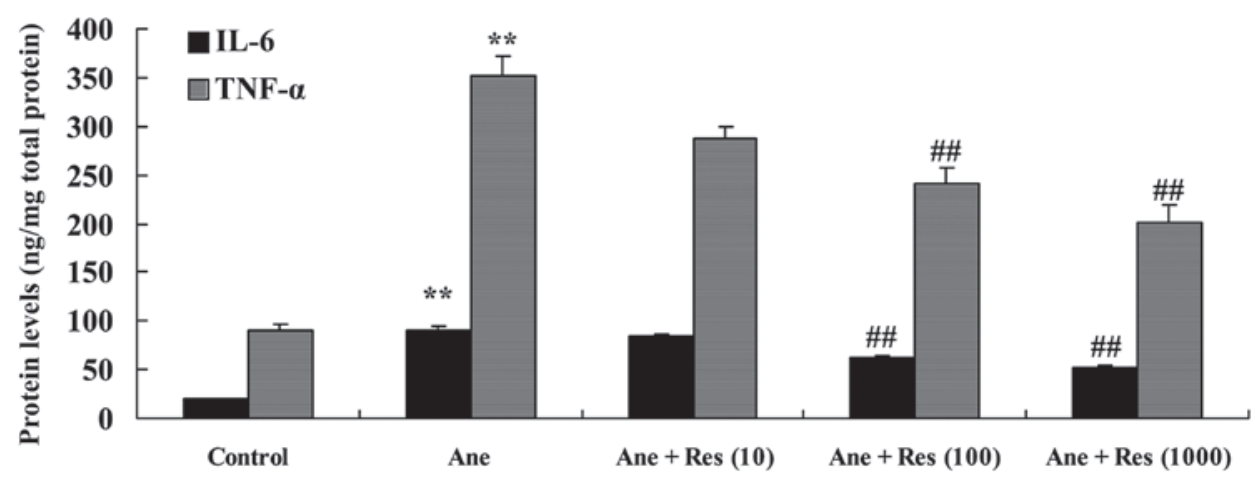

Figure 3. Resveratrol protects neuronal cells from isoflurane-induced inflammation. Groups: Control, control group; Ane, anesthesia-induced model group; Ane + Res (10), $10 \mu \mathrm{M}$ resveratrol + anesthesia-induced model group; Ane + Res (100), $100 \mu \mathrm{M}$ resveratrol + anesthesia-induced model group; Ane + Res (1,000), $1,000 \mu \mathrm{M}$ resveratrol + anesthesia-induced model group. ${ }^{* *} \mathrm{P}<0.01$ compared with control group; ${ }^{\# \#} \mathrm{P}<0.01$ compared with Ane model group. IL, interleukin; $\mathrm{TNF}$, tumor necrosis factor.

apoptosis of isoflurane-induced PC12 cells in a dose-dependent manner (Fig. 2).

Resveratrol protects neuronal cells from isoflurane-induced inflammation. To evaluate the effects of resveratrol on isoflurane-induced inflammation of neuronal cells, IL-6 and TNF- $\alpha$ activities were examined. As compared with those in the control group, isoflurane treatment was observed to cause significant increases in IL- 6 and THF- $\alpha$ activities, which was inhibited by pretreatment with resveratrol (Fig. 3).

Resveratrol protects neuronal cells from isoflurane-induced oxidative stress. The effect of resveratrol pretreatment on isoflurane-induced oxidative stress in neuronal cells was also assessed. Following treatment with isoflurane, MDA was increased and SOD activity was inhibited as compared with the control group (Fig. 4). However, pretreatment with resveratrol observably inhibited the isoflurane-induced oxidative stress in PC12 cells (Fig. 4).
Resveratrol inhibits isoflurane-induced caspase-3 activation in neuronal cells. In order to assess the effect of resveratrol on caspase- 3 in anesthesia-induced neuronal cells, caspase- 3 activity was measured using a kit. The results demonstrated that isoflurane markedly promoted caspase- 3 activity in PC12 cells, as compared with that in the control group. Treatment with resveratrol significantly inhibited isoflurane-induced caspase-3 activity in PC12 cells (Fig. 5).

Resveratrol inhibits isoflurane-induced iNOS expression in neuronal cells. The effect of resveratrol on anesthesia-induced iNOS expression in PC12 cells was assessed. As presented in Fig. 6, isoflurane induced iNOS protein expression in PC12 cells. Resveratrol pretreatment significantly inhibited the isoflurane-induced iNOS protein expression in PC12 cells (Fig. 6).

Resveratrol attenuates the isoflurane-induced inhibition of phosphoinositide-3 kinase (PI3K)/Akt signaling in neuronal 


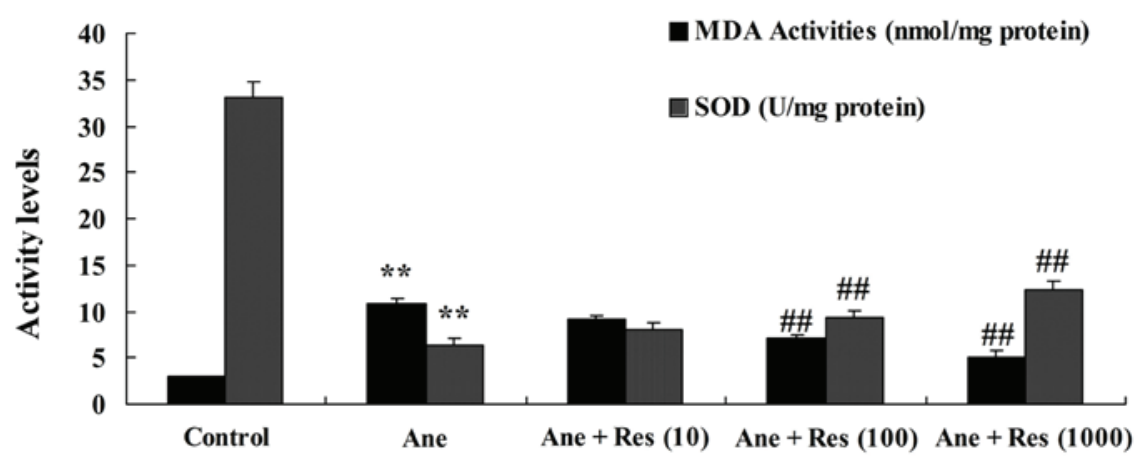

Figure 4. Resveratrol inhibits isoflurane-induced oxidative stress in neuronal cells. Groups: Control, control group; Ane, anesthesia-induced model group; Ane + Res (10), $10 \mu \mathrm{M}$ resveratrol + anesthesia-induced model group; Ane + Res (100), $100 \mu \mathrm{M}$ resveratrol + anesthesia-induced model group; Ane + Res $(1,000), 1,000 \mu \mathrm{M}$ resveratrol + anesthesia-induced model group. ${ }^{* *} \mathrm{P}<0.01$ compared with control group; ${ }^{\# \#} \mathrm{P}<0.01$ compared with Ane model group. MDA, malondialdehyde; SOD, superoxide dismutase.

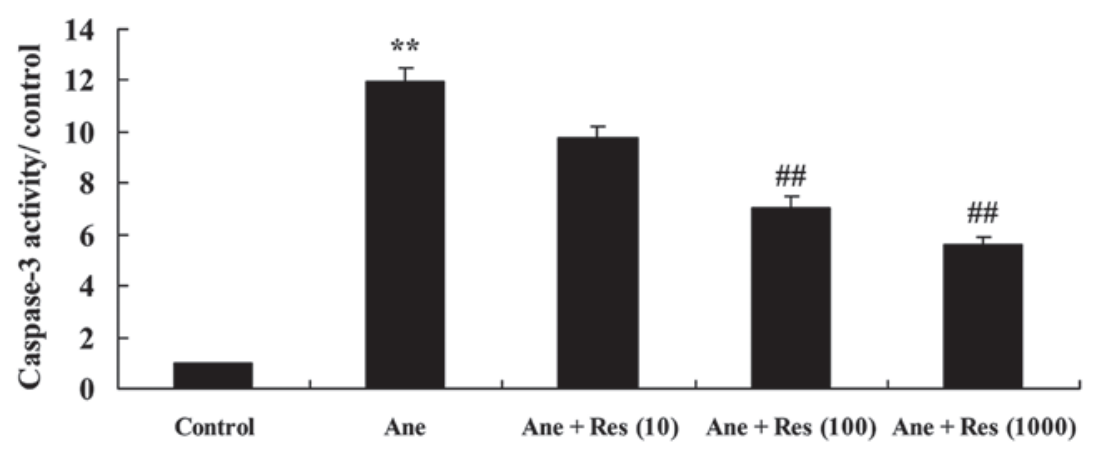

Figure 5. Resveratrol inhibits isoflurane-induced caspase-3 activation in neuronal cells. Groups: Control, control group; Ane, anesthesia-induced model group; Ane + Res (10), $10 \mu \mathrm{M}$ resveratrol + anesthesia-induced model group; Ane + Res (100), $100 \mu \mathrm{M}$ resveratrol + anesthesia-induced model group; Ane + Res $(1,000), 1,000 \mu \mathrm{M}$ resveratrol + anesthesia-induced model group. ${ }^{* *} \mathrm{P}<0.01$ compared with control group; ${ }^{\# \#} \mathrm{P}<0.01$ compared with Ane model group.

cells. The present study also identified the effect of resveratrol on anesthesia-induced PI3K/Akt activation in neuronal cells. The p-Akt/Akt ratio was significantly suppressed by isoflurane in PC12 cells (Fig. 7). Of note, resveratrol significantly attenuated the isoflurane-induced inhibition of the p-Akt/Akt ratio in PC12 cells (Fig. 7).

Resveratrol inhibits isoflurane-induced p38 MAPK signaling in neuronal cells. To evaluate the effect of resveratrol on the p38 MAPK signaling pathway in anesthesia-induced neuronal cells, the protein levels of p-p38 and p38 were measured using western blot analysis. Isoflurane was found to induce p-p38 MAPK in PC12 cells compared with that in the vehicle control group (Fig. 8). However, resveratrol treatment significantly suppressed the isoflurane-induced p-p38/p38 MAPK protein ratio in PC12 cells (Fig. 8).

\section{Discussion}

With the advantages of rapidly taking effect, short maintenance time, fast and complete awakening and no accumulation after continuous infusion, isoflurane has become a widely used intravenous anesthetic (3). Isoflurane was found to have sedation and hypnotic effects and to be a mediator of the inflammatory response and oxidative stress injury (14). It has been proven that the increase of oxygen free radical injury, respiratory burst of neutrophils and adhesion factors as well as the production of inflammatory cytokines, increases of apoptosis and the synthesis of high-energy phosphates are manifestations of the anti-inflammatory actions of isoflurane (15). The present study evaluated the capacity of resveratrol to attenuate the inhibition rate and apoptotic effects of isoflurane on PC12 cells and to suppress the associated inflammation and oxidative stress. Bai et al (16) demonstrated that treatment with resveratrol restrained isoflurane-induced neuroapoptosis by activating the Akt signaling pathway. Xu et al (17) demonstrated that resveratrol inhibited hypoxia-induced oxidative stress and inflammation in lungs of neonatal rats.

As a neurotransmitter, NO has an information transfer function and participates in neurodevelopment as well as in the regulation and guidance of axonal growth (18). It has an important role in learning and memory, which is manifested by the fact that $\mathrm{NO}$ affects the long-term potentiation of synapses and regulates the release of neurotransmitters associated with learning as well as memory enhancement (19). The results of the present study demonstrated that resveratrol inhibited anesthesia-induced iNOS protein expression in PC12 cells. Huang et al (20) indicated that resveratrol inhibits oxygen-glucose deprivation-induced iNOS, caspase-3 and $\mathrm{B}$-cell lymphoma-2 (Bcl-2)/Bcl-2-associated $\mathrm{X}$ protein signaling.

It is universally held that cell apoptosis results from cascade events involving a series of highly regulated cysteine proteases (caspases) (21). Caspase-3 has been proved to 

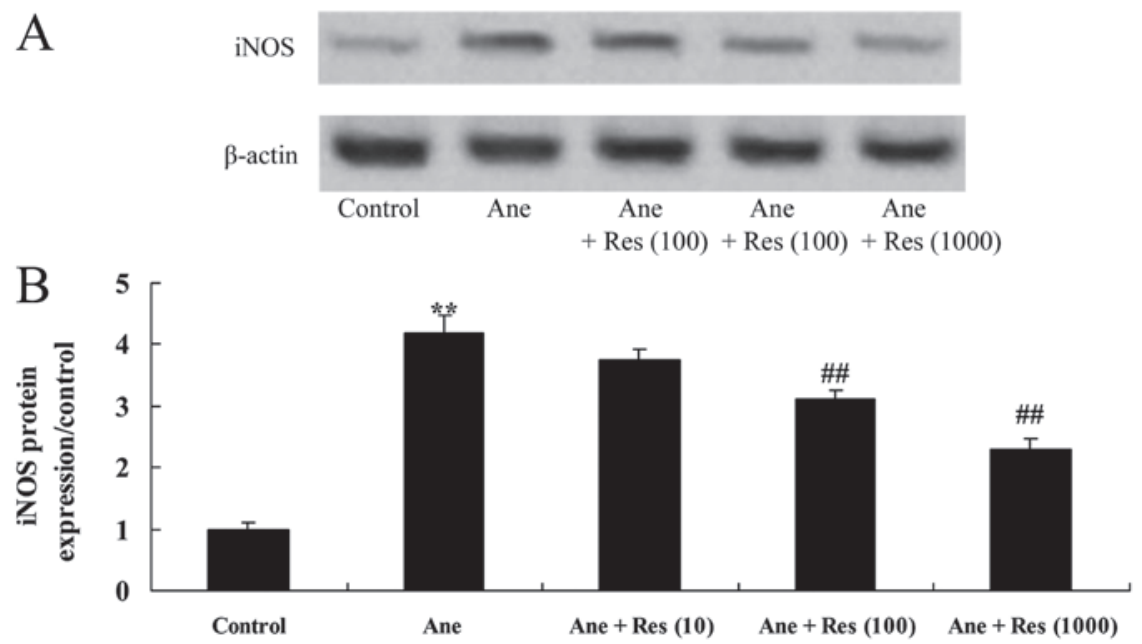

Figure6.Resveratrolinhibitsisoflurane-inducediNOSinneuronalcells.(A)WesternblotshowingtheiNOSproteinexpressioninisoflurane-induced/resveratrol-treated neuronal cells. (B) Quantified expression levels of iNOS in each group. Groups: Control, control group; Ane, anesthesia-induced model group; Ane + Res (10), $10 \mu \mathrm{M}$ resveratrol + anesthesia-induced model group; Ane + Res (100), $100 \mu \mathrm{M}$ resveratrol + anesthesia-induced model group; Ane + Res $(1,000), 1,000 \mu \mathrm{M}$ resveratrol + anesthesia-induced model group. ${ }^{* *} \mathrm{P}<0.01$ compared with control group; ${ }^{\# \#} \mathrm{P}<0.01$ compared with Ane model group. iNOS, inducible nitric oxide synthase.

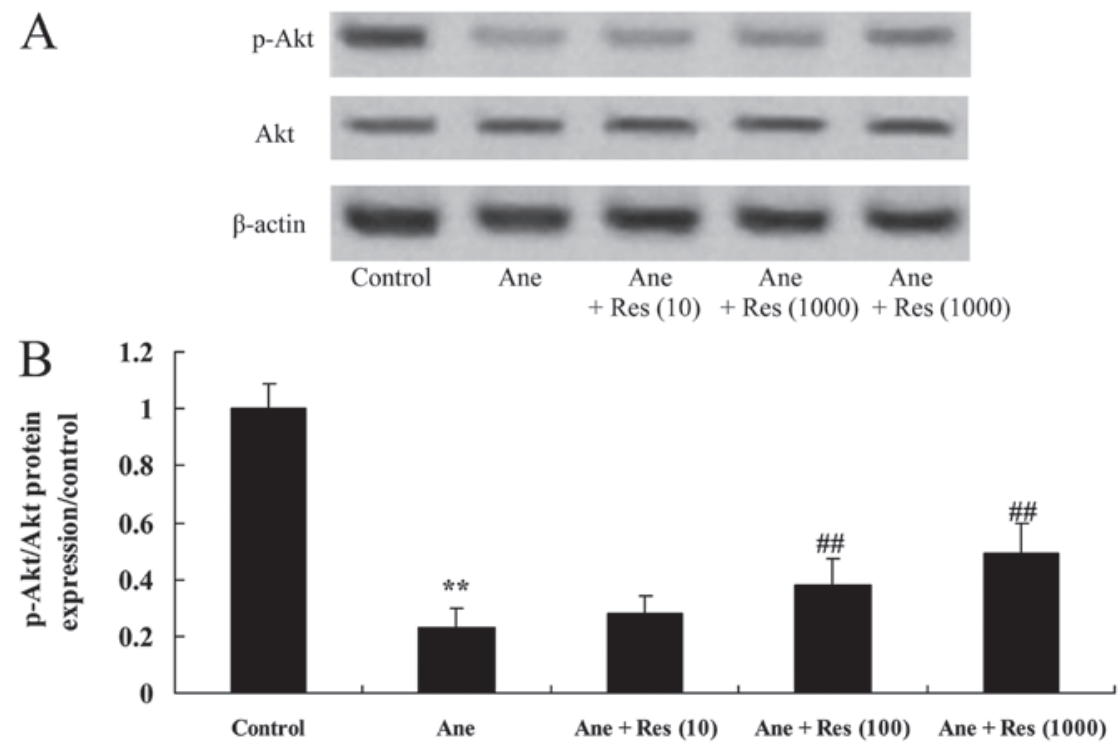

Figure 7. Resveratrol inhibits isoflurane-induced decreases of Akt activation in neuronal cells. (A) Western blot showing the protein levels of Akt and p-Akt in isoflurane-induced/resveratrol-treated neuronal cells. (B) Quantified p-Akt/Akt ratio in each group. Groups: Control, control group; Ane, anesthesia-induced model group; Ane + Res (10), $10 \mu \mathrm{M}$ resveratrol + anesthesia-induced model group; Ane + Res (100), $100 \mu \mathrm{M}$ resveratrol + anesthesia-induced model group; Ane + Res $(1,000), 1,000 \mu \mathrm{M}$ resveratrol + anesthesia-induced model group. ${ }^{* *} \mathrm{P}<0.01$ compared with control group; ${ }^{\# \#} \mathrm{P}<0.01$ compared with Ane model group. p-Akt, phosphorylated Akt.
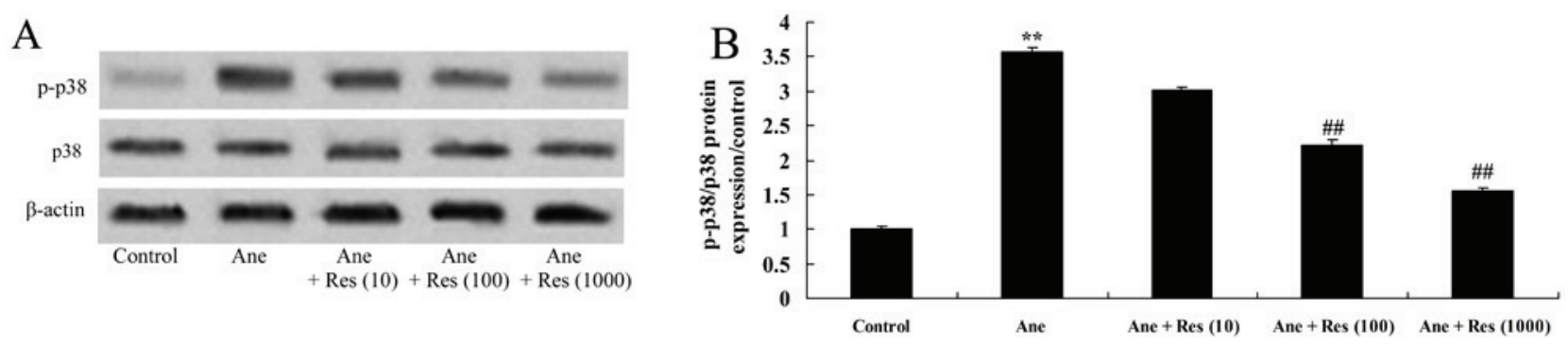

Figure 8. Resveratrol inhibits isoflurane-induced increases of p-p38 MAPK in neuronal cells. (A) Western blot showing the protein levels of p-p38 and p38 MAPK in isoflurane-induced/resveratrol-treated neuronal cells. (B) Quantified p-p38/p38 MAPK ratio in each group. Groups: Control, control group; Ane, anesthesia-induced model group; Ane + Res (10), $10 \mu \mathrm{M}$ resveratrol + anesthesia-induced model group; Ane + Res (100), $100 \mu \mathrm{M}$ resveratrol + anesthesia-induced model group; Ane $+\operatorname{Res}(1,000), 1,000 \mu \mathrm{M}$ resveratrol + anesthesia-induced model group. ${ }^{* *} \mathrm{P}<0.01$ compared with control group; ${ }^{\# \#} \mathrm{P}<0.01$ compared with Ane model group. p-p38 MAPK, phosphorylated p38 mitogen-activated protein kinase. 
function downstream of the cascade reactions, where it causes cellular death by degrading corresponding substrates in cells (22). However, the true regulators of apoptosis may be its downstream signaling components. As a transmembrane glycoprotein, $\beta$-amyloid precursor protein may be cut by caspase- 3 and from its protein hydrolysate, amyloid $\beta$-peptide may be formed through aggregation (23). Furthermore, it may induce the activation of caspase-3 and promote apoptosis of cells. The present study found that resveratrol inhibits anesthesia-induced caspase- 3 activation in PC12 cells.

After anesthesia induction, a large number of free radicals are produced. Toxic amino acids activate apoptosis-associated genes, which initiate apoptotic signaling pathways to promote apoptosis and necrosis of nerve cells (24). The Akt signaling pathway participates in apoptosis and is closely associated with cerebral ischemic injury (25). The present study also found that resveratrol attenuated the isoflurane-induced inhibition of the p-Akt/Akt rate in PC12 cells. Bai et al (16) demonstrated that treatment with resveratrol restrained isoflurane-induced neuroapoptosis by activating the Akt signaling pathway. Campagnolo et al (26) reported that resveratrol reduced neointimal formation in a vascular graft model through microRNA-21/Akt/ $\beta$-catenin.

Hyperglycemia, abnormal hemodynamics, oxidative stress and pro-inflammatory cytokines activate p38/MAPK signaling pathways (27). As downstream events of p38/MAPK activation, inflammatory cells are induced, the expression of inflammatory mediators is promoted and the production of inflammatory cytokines is increased. Finally, renal inflammatory lesions occur (28). In line with this, the present study found that resveratrol treatment significantly suppressed the isoflurane-induced increase in the p-p38/p38 MAPK ratio in PC12 cells. Chun et al (29) suggested that resveratrol downregulates acute thromboembolism-induced pulmonary artery hypertension through p38 MAPK in rats.

\section{References}

1. Zhao K, Xu XS, Meng X, Li YL, Li JF and Chen WQ: Autophagy of monocytes attenuates the vulnerability of coronary atherosclerotic plaques. Coron Artery Dis 24: 651-656, 2013.

2. Sabe AA, Elmadhun NY, Sadek AA, Chu LM, Bianchi C and Sellke FW: Differential effects of atorvastatin on autophagy in ischemic and nonischemic myocardium in Ossabaw swine with metabolic syndrome. J Thorac Cardiovasc Surg 148: 3172-3178, 2014.

3. Zhang F, Zhu ZQ, Liu DX, Zhang C, Gong QH and Zhu YH: Emulsified isoflurane anesthesia decreases brain-derived neurotrophic factor expression and induces cognitive dysfunction in adult rats. Exp Ther Med 8: 471-477, 2014.

4. Cheng J, Qiao L, Xu X, Zhai C, Zhao K, Ji X and Chen W: Lower AMP-activated protein kinase level is associated with the vulnerability of coronary atherosclerotic plaques by attenuating the expression of monocyte autophagy. Coron Artery Dis 26: 322-327, 2015.

5. Liu W, Guo Q, Hu X, Peng L and Zhou B: Induction of DJ-1 protects neuronal cells from isoflurane induced neurotoxicity. Metab Brain Dis 30: 703-709, 2015.

6. Wang H, Fan J, Li NL, Li JT, Yuan SF, Yi J, Wang L, Chen JH, Lv YG, Yao Q, et al: A subanesthetic dose of isoflurane during postconditioning ameliorates zymosan-induced neutrophil inflammation lung injury and mortality in mice. Mediators Inflamm 2013: 479628, 2013.

7. Frithiof R, Soehnlein O, Eriksson S, Fenhammar J, Hjelmqvist H, Lindbom L and Rundgren M: The effects of isoflurane anesthesia and mechanical ventilation on renal function during endotoxemia. Acta Anaesthesiol Scand 55: 401-410, 2011.
8. Wang W, Bansal S, Falk S, Ljubanovic D and Schrier R: Ghrelin protects mice against endotoxemia-induced acute kidney injury. Am J Physiol Renal Physiol 297: F1032-F1037, 2009.

9. Malhotra A, Bath S and Elbarbry F: An organ system approach to explore the antioxidative, anti-inflammatory, and cytoprotective actions of resveratrol. Oxid Med Cell Longev 2015: 803971, 2015.

10. Liu FC, Tsai HI and Yu HP: Organ-protective effects of red wine extract, resveratrol, in oxidative stress-mediated reperfusion injury. Oxid Med Cell Longev 2015: 568634, 2015.

11. Park EJ and Pezzuto JM: The pharmacology of resveratrol in animals and humans. Biochim Biophys Acta 1852: 1071-1113, 2015.

12. Dobrzyńska MM: Resveratrol as promising natural radioprotector. A review. Rocz Panstw Zakl Hig 64: 255-262, 2013.

13. Zhang Y, Xu Z, Wang H, Dong Y, Shi HN, Culley DJ, Crosby G, Marcantonio ER, Tanzi RE and Xie Z: Anesthetics isoflurane and desflurane differently affect mitochondrial function, learning, and memory. Ann Neurol 71: 687-698, 2012.

14. Cho SS, Rudloff I, Berger PJ, Irwin MG, Nold MF, Cheng W and Nold-Petry CA: Remifentanil ameliorates intestinal ischemia-reperfusion injury. BMC Gastroenterol 13: 69, 2013.

15. Allaouchiche B, Debon R, Goudable J, Chassard D and Duflo F: Oxidative stress status during exposure to propofol, sevoflurane and desflurane. Anesth Analg 93: 981-985, 2001.

16. Bai T, Dong DS and Pei L: Resveratrol mitigates isoflurane-induced neuroapoptosis by inhibiting the activation of the Akt-regulated mitochondrial apoptotic signaling pathway. Int $\mathrm{J}$ Mol Med 32: 819-826, 2013.

17. Xu W, Zhao Y, Zhang B, Xu B, Yang Y, Wang Y and Liu C: Resveratrol attenuates hyperoxia-induced oxidative stress, inflammation and fibrosis and suppresses wnt/ $\beta$-catenin signaling in lungs of neonatal rats. Clin Exp Pharmacol Physiol 42: 1075-1083, 2015.

18. Li L, Avery R, Budev M, Mossad S and Danziger-Isakov L: Oral versus inhaled ribavirin therapy for respiratory syncytial virus infection after lung transplantation. J Heart Lung Transplant 31: 839-844, 2012.

19. Piedimonte G and Perez MK: Respiratory syncytial virus infection and bronchiolitis. Pediatr Rev 35: 519-530, 2014.

20. Huang T, Gao D, Jiang X, Hu S, Zhang L and Fei Z: Resveratrol inhibits oxygen-glucose deprivation-induced MMP-3 expression and cell apoptosis in primary cortical cells via the NF- $\kappa B$ pathway. Mol Med Rep 10: 1065-1071, 2014.

21. Weng K, Zhang J, Mei X, Wu A, Zhang B, Cai M, Zheng Y and Ke Z: Lower number of plasmacytoid dendritic cells in peripheral blood of children with bronchiolitis following respiratory syncytial virus infection. Influenza Other Respir Viruses 8: 469-473, 2014.

22. Ciencewicki JM, Wang X, Marzec J, Serra ME, Bell DA, Polack FP and Kleeberger SR: A genetic model of differential susceptibility to human respiratory syncytial virus (RSV) infection. FASEB J 28: 1947-1956, 2014.

23. Hacımustafaoğlu M, Celebi S, Bozdemir SE, Ozgür T, Ozcan I, Güray A and Cakır D: RSV frequency in children below 2 years hospitalized for lower respiratory tract infections. Turk J Pediatr 55: 130-139, 2013.

24. Weiss ID, Wald O, Wald H, Beider K, Abraham M, Galun E, Nagler A and Peled A: IFN-gamma treatment at early stages of influenza virus infection protects mice from death in a NK cell-dependent manner. J Interferon Cytokine Res 30: 439-449, 2010.

25. Uozaki $\mathrm{H}$ and Fukayama M: Epstein-Barr virus and gastric carcinoma-viral carcinogenesis through epigenetic mechanisms. Int J Clin Exp Pathol 1: 198-216, 2008.

26. Campagnolo P, Hong X, di Bernardini E, Smyrnias I, Hu Y and $\mathrm{Xu}$ Q: Resveratrol-induced vascular progenitor differentiation towards endothelial lineage via MiR-21/Akt/ $\beta$-catenin is protective in vessel graft models. PLoS One 10: e0125122, 2015.

27. Du L, Zhang X, Liu J and Jiang S: Protocol for recombinant RBD-based SARS vaccines: Protein preparation, animal vaccination and neutralization detection. J Vis Exp: pii: 2444,2011

28. Halfpenny KC and Wright DW: Nanoparticle detection of respiratory infection. Wiley Interdiscip Rev Nanomed Nanobiotechnol 2: 277-290, 2010.

29. Chun C, Yang W, Xueding C, Qi Z, Xiaoying H, Honglei X, Fangyou Y, Chan C, Yuanyuan L, Weixi Z, et al: Resveratrol downregulates acute pulmonary thromboembolism-induced pulmonary artery hypertension via $\mathrm{p} 38$ mitogen-activated protein kinase and monocyte chemoattractant protein-1 signaling in rats. Life Sci 90: 721-727, 2012. 